\title{
Canto pré-natal: alquimias sonoras para gestantes
}

\author{
JANAÍNA TRÄSEL MARTINS
}




\section{- RESUMO}

Este artigo irá focar no canto pré-natal; nos benefícios da música e do canto durante a gestação; na audição do feto no ventre e na escuta da gestante do seu corpo. Como metodologia para pesquisar sobre estes temas foram realizados estudos teóricos nas áreas da musicoterapia obstétrica, da terapia sonora e da medicina e também foram realizadas práticas de canto pré-natal. Arte, movimento e saúde são integrados com as alquimias sonoras para ampliar a consciência da corporeidade da mulher durante a gestação. Com cantos femininos em um círculo de mulheres, nos apoiamos e nos fortalecemos durante a gestação e enviamos vibrações sonoras harmoniosas para o bebê no ventre.

\section{PALAVRAS-CAVE}

Canto pré-natal, música pré-natal, gestação, escuta, consciência.

\section{ABSTRACT}

This article will focus on prenatal singing; on the benefits of music and singing during pregnancy; on the baby's hearing in the womb and on the listening of the pregnant woman to her body. To determine the methodology for researching these themes, theoretical studies were done in obstetrical music therapy, sound therapy, medicine and also practical research in prenatal singing classes. Art, movement and health are integrated with sound alchemy to widen the woman's body awareness during pregnancy. With feminine chants in a circle of women, we support and strengthen ourselves during pregnancy and we send harmonious sounds vibrations to the baby in the womb.

\section{KEYWORDS}

Prenatal singing, prenatal music, pregnancy, listening, consciousness.

\section{Introdução}

Quais os benefícios da música e do canto materno durante a gestação? Como ocorre a audição no feto? Para pesquisar sobre tais temas, mergulharemos nos estudos da medicina, da musicoterapia obstétrica, no meu relato da pesquisa prática das aulas de canto pré-natal que eu conduzi e nos depoimentos escritos das gestantes que participaram das aulas no primeiro semestre de 2016.

As aulas de canto pré-natal fazem parte das atividades de extensão do projeto "Cantos de Gaia: alquimias sonoras", vinculado ao Grupo de Pesquisa Poéticas da Voz, da Universidade Federal de Santa Catarina. Os encontros aconteceram semanalmente, com 2 horas de duração, de maio a julho de 2016. Em média haviam nas aulas por volta de 12 gestantes, com idades entre 20 a 42 anos e com diferentes idades gestacionais, variando entre 12 e 37 semanas de gestação.

Nas práticas de canto pré-natal trabalhamos nos encontros com cantos e músicas para o corpo feminino e para o bebê no ventre. Os objetivos eram: ampliar a consciência da sabedoria corporal da mulher, o empoderamento feminino, a expressão dos sentimentos da gestante, a comunicação afetiva entre gestante e o 
bebê no ventre.

A metodologia das aulas de canto pré-natal envolveu cantos femininos, jogos lúdicos de improvisação musical e vocal; meditações sonoras com visualizações criativas; banho de sons (sound bath); danças circulares cantadas, exercícios corporais de respiração e de voz para a preparação para o parto; improvisações sonoras com instrumentos musicais (kântele, kalimba, tigelas de cristal, sinos, carriIhões, tambores xamânicos, chocalhos, violão).

Nas aulas de canto pré-natal as práticas foram conduzidas levando em consideração a consciência fisiológica da produção vocal (respiração, articulação, ressonância vocal, apoios musculares) aliada à dimensão afetiva do ato de cantar. A produção vocal é percebida a partir do seu potencial de ação, de afeto: por meio de suas frequências vibratórias sonoras, a voz toca, afeta o corpo da gestante e do bebê. O terapeuta do som, o americano Jonathan Goldman (2008) considera o som como uma onda que carrega as frequências vibratórias das intenções. As intenções envolvem a qualidade vibratória dos pensamentos, visualizações, sentimentos. Goldman (2011) fala da potência afetiva que é a união da vocalização + visualização + intenção, lembrando da importância da consciência do sentimento que é projeto no som.

Levando isto em consideração, os procedimentos pedagógicos das aulas trabalhavam na vocalização a consciência das sensações corpóreas da gestante, a intenção e a visualização criativa do que se deseja irradiar para o bebê. As letras das canções e os exercícios corpóreo-vocais eram conduzidos para o despertar do empoderamento, de conexão e de confiança na natureza do corpo feminino. As vivências convidavam à ampliação da escuta: da escuta de si, do seu corpo, das sensações, do bebê, do ambiente e das outras gestantes. Um convite à escuta dos processos internos despertados através dos sons, observando a interação entre as sonoridades e as sensações corpóreas, sentimentos, imagens, pensamentos. Para gerar esta escuta, com as vocalizações adentrávamos em uma jornada interior, ampliando a consciência para realizar as alquimias sonoras repletas de afeto.

$\mathrm{O}$ ato de cantar como prática alquímica consciente era enfocado na busca das qualidades vibratórias do canto, a qual era pesquisada/sentida através da repetição contínua do canto. Ficávamos um bom tempo cantando a mesma canção. Esta repetição do canto nos fazia ir além do aspecto semântico das palavras e nos fazia adentrar no potencial das frequências vibratórias das ondas sonoras. Com o movimento vibratório da afetividade despertado no cantar, há liberação de neurohormônios. Constata as pesquisas de Jonathan Goldman:

Através do uso de intencionalidade juntamente com os harmônicos da voz, vários locais do cérebro podem ser estimulados, causando a liberação de neurotransmissores poderosos como a melatonina e as endorfinas (substâncias naturalmente criadas) e outras químicas ainda a serem descobertas (GOLDMAN, 1998, p. 34) (tradução nossa). ${ }^{1}$

\footnotetext{
${ }^{1}$ No original: "Through use of intentionality coupled with specific vocal harmonics, various sites throughout the brain can be stimulated, causing the release of powerful neurochemicals such as melatonin and the endorphins (naturally created substances) and other chemicals yet to be discovered" (GOLDMAN, 1998, p. 34). 
Os sons movem as energias do corpo, estimula a liberação dos hormônios, desperta as emoções. No ato de cantar a mulher grávida libera hormônios que são benéficos para a gestação e também para a hora do parto, como diz Janet Balaskas, no seu livro "Parto Ativo": "Emitir sons ajuda a produzir hormônios semelhantes às endorfinas que agem como analgésicos internos naturais e ajudam na alteração da consciência" (BALASKAS, 2015, p. 204).

Vocalizar amplia a conexão com o corpo e com o bebê, na gestação e no parto. O médico francês, o obstetra Frédérick Leboyer constata que:

A mulher que em seus exercícios preparatórios pratica cantar e falar as vogais o mais perfeitamente possível, irá trabalhar intensamente com os lábios e com a boca, o que também - misteriosamente, mas, sem dúvida - tem um efeito definitivo sobre o colo do útero, que se alarga de forma supremamente harmônica e suave sob a influência dos exercícios, no mínimo fazendo as contrações serem menos doloridas (LEBOYER, 2009, p. 85) (tradução nossa).²

Levando-se estas premissas em consideração, os fundamentos pedagógicos que guiavam as aulas de canto com as gestantes eram calcados em uma jornada interior: cada corpo com a sua história compunha a sua alquimia sonora, misturando sentimentos e afetos nas vocalizações e irradiando-as para o bebê no ventre.

Nos próximos itens será desenvolvido sobre a escuta do bebê no ventre e sobre a escuta da gestante de seu corpo.

\section{A audição do feto no ventre:}

Nesta relação interativa entre mãe e bebê por meio do som, como e quando o feto dentro do útero escuta?

O musicoterapeuta, argentino, Gabriel Federico, que trabalha com mulheres grávidas e a música pré-natal, constata que os sons que compõe o ambiente acústico do bebê são os sons do corpo da mamãe (atividade cardiovascular, das vísceras, aparelho digestivo, do ritmo respiratório, da circulação do sangue pelo cordão), os sons dos movimentos dos músculos do proprio bebê e a voz da mamãe. A partir do quarto mês de idade gestacional o feto escuta os ruídos exteriores atenuados pela parede abdominal e pela interface entre o meio aéreo e o meio líquido. Entre esses sons, a batida do coração da mãe é predominante (FEDERICO, 2001).

Federico assinala 3 vias de recebimento do som pelo o bebê: a sensitiva, a auditiva e a hormonal. A sensitiva é a que permite sentir no corpo as vibrações que produz o som. A via auditiva é a que capta os sons mais agudos, aqueles que atravessam de forma mais direta a parede abdominal e que o bebê pode ouvir melhor, pois é ativada a cadeia de ossículos do aparelho auditivo que envia a informação ao cérebro. A terceira via, a hormonal, é a via que transmite a sensação que tem a mãe daquilo que está escutando (FEDERICO, 2013).

\footnotetext{
2 No original: "The woman who practices singing and speaking the vowels as perfectly as possible in her preparatory exercises will be led to work very intensively with her lips and mouth, which also - mysteriously but unquestionably - has a definitive effect on the cervix, which widens in a supremely harmonic and smooth manner under the influence of the exercises, at the very least making the contractions less painful" (LEBOYER, 2009, p. 85).
} 
No artigo "Experiência auditiva no meio intrauterino" a mestranda em psicologia Patricia Nunes (2009) faz um levantamento sobre estudos realizados em relação ao desenvolvimento do sistema auditivo do feto e a capacidade de audição. Ela compartilha os seguintes estudos: a) Klaus e Klaus (1989) ${ }^{3}$ averiguam que a partir da 20 a semana de gestação a cóclea atua, o que permite que o feto reaja a estímulos sonoros intensos; no quarto mês de gestação o tímpano está completamente formado e o sistema auditivo funcionando; no quinto mês de gestação o feto já possui as estruturas do ouvido médio e do ouvido interno formados, e no sexto mês de gestação as fibras do nervo auditivo começam a mielenizar-se; b) Verri (1999) ${ }^{4}$ observa que o feto tem a capacidade de ouvir e desenvolver a memória dos sons intra-utero. $O$ feto pode detectar, responder e diferenciar sons, assim como a sua intensidade e altura.

Federico constata que a audição intrauterina pode variar entre o meio líquido e o ósseo:

Se um feto de 8 meses está em posição cefálica, de cabeça para baixo, ele receberá o som através da condução óssea, pois sua cabeça está apoiada diretamente sobre os ossos da pelve de sua mãe. E se o bebê está em posição podálica, sua cabeça estará mais perto da placenta e do coração materno (FEDERICO, 2013, p.105).

Sobre as frequências escutadas pelo bebê, os médicos constatam que: "em geral, os sons mais graves são os que ele sente mais intensamente" (FEDERICO, 2013, p.112). "Os sons graves chegam mais fortes que os sons agudos, devido a vibração que provocam no meio líquido" (Matias, 1999 apud Nunes, 2009, p.2). "O feto ouve toda uma gama de sons constituída predominantemente por vibrações de baixa frequência" (Tomatis apud GAYNER, 1999, p.83).

O Dr. Julio Tresierra Cabrera, do Serviço de Neonatologia do Hospital Nacional Guillermo Almenara Irigoyen, no seu artigo "Musicoterpia y pediatría" conta que através dos estudos com ecografias foi possível observar que o feto é capaz de reconhecer músicas. Tais observações foram constatadas pelos movimentos do feto: da respiração, da abertura e fechamento das pálpebras, da cabeça seguindo a fonte emissora do som, dos movimentos dos membros superiores e inferiores (CABRERA, 2005). Gabriel Federico (2003) constata que quando o feto é exposto ao estímulo músical que já conhece, ele tem reações como piscar, sugar e seguir a fonte emissora do som. E que as músicas que o bebê sente no interior do útero são memorizadas por ele. E que: "o bebê se relacionará com as melodias que escutará dentro do útero e que estimularão seu sistema neurovegetativo" (FEDERICO, 2001, p.299) (tradução nossa) ${ }^{5}$.

\footnotetext{
${ }^{3}$ KLAUS, M. \& KLAUS, P. O surpreendente recém-nascido. PA: Artes Médicas, 1989.

${ }^{4}$ VERRI, G. A gestante exposta ao ruído. Efeitos auditivos para o feto. Porto Alegre: Centro de Especialização em Fonoaudiologia Clínica (CEFAC), 1999.

5 No original: "The baby will be drawn to the melodies that will be remembered in utero, and these will stimulate its neural axis" (FEDERICO, 2001, p.299).
} 
Entre os benefícios da música para o feto, estudos apontam que: "a música vai aumentar o movimento de seus membros, melhorando assim o consumo de oxigênio através de um aumento geral da troca de fluidos" (FEDERICO, 2001, p. 299) (tradução nossa) 6 . A música opera como um neurotransmissor interativo atuando diretamente sobre o sistema pituitário do feto (CABRERA, 2005). Federico observa que:

A música funciona como um neurotransmissor inter-ativo que afeta o sistema celular e a hipófise do feto. Isso define uma faixa de uma variedade de sensações que serão registradas pelo feto, e irá lembra-lo das experiências agradáveis que viveu enquanto estava no útero (FEDERICO, 2001, p.299) (tradução nossa). ${ }^{7}$

Estes aspectos fisiológicos da audição são interconectados com a escuta afetiva do feto no ventre: a voz da mãe é onda sonora composta por frequências vibratórias que carregam afetos. O médico otorrinolaringologista francês, Dr. Alfred Tomatis (1987), que vem estudando há mais de 50 anos as funções do ouvido humano e a importância da audição, no seu livro "A noite uterina" fala sobre a escuta intrauterina: ele assinala a importância da voz materna como sendo um "núcleo vibratório de amor", que é "para além de toda a semântica, de toda a fibra afetiva, uma verdadeira linguagem" (TOMATIS, 1987, p. 160). Ele diz que:

A voz materna constitui, indubitavelmente, a 'massa sonora' sobre a qual se vai moldar a linguagem. A mãe exprime o seu vivido, os seus sentimentos e, em particular, o seu amor materno através de um material acústico bem específico percebido de uma forma singular pelo feto (TOMATIS, 1987, p. 157).

As vibrações sonoras da voz materna são compostas de frequências que carregam em suas ondas as sensações, os afetos, os sentimentos.

Sobre a escuta do bebê no ventre, algumas gestantes que participaram das aulas de canto pré-natal escreveram:

Durante o período que participei dos encontros (minha idade gestacional no início era de 10 semanas) mesmo que o feto não estivesse na etapa em que ouve a voz da mãe; eu sentia que vibração da minha voz, por meio dos cantos, ecoava até ele, enviando sensações e sentimentos, que tenho certeza que ele sentia (Franciele, 25 anos).

Quando participei do projeto (12 a 17 semanas) a minha bebê ainda não possuia aparelho auditivo completo, mas acredito que o grande ganho foram os momentos de prazer vividos nas aulas e sentidos por ela em especial pelas vibrações e pelas endorfinas trocadas comigo durante os encontros (Marina, 38 anos).

\footnotetext{
${ }^{6}$ No original: "Music will also enhance active movement of its limbs thus improving oxygen intake via a general increase of the exchange of fluids" (FEDERICO, 2001, p.299).

${ }^{7}$ No original: "Music works as an inter-active neurotransmitter affecting the cellular system and the hypophysis of the fetus. This sets a track of a variety of sensations that will be recorded by the fetus and remind him of the pleasant experiences he lived while in utero" (FEDERICO, 2001, p.299).
} 
Sentia que os nossos bebês além de poder ouvir sons harmônicos durante esse período desfrutaram das vibrações emanadas pelas nossas intenções ali reunidas (Michele, 42 anos).

Quando comecei no grupo, eu estava numa fase gestacional muito boa, a audição da minha filha já se encontrava bem desenvolvida, portanto foi possível sentir mais sutilmente as reações dela dentro de mim. Eu vi no canto um estímulo para uma maior aproximação entre nós duas, algo além do útero, além do físico, foi uma oportunidade de ficarmos mais íntimas também espiritualmente (Hévila, 31 anos).

A escuta do feto no ventre, como vimos neste item, pode ser via sensitiva (das vibrações), via auditiva (a partir da 20aㅡ semana), via hormonal (dos sentimentos). Levando estes estudos em consideração, as vivências sonoras das aulas de canto pré-natal convidavam as gestantes a ampliar a escuta sobre o que os sons provocam no corpo. Uma escuta da força criativa da ação vocal materna, visando tocar o corpo do bebê com vibrações sonoras de afetivas.

\section{A escuta e a voz da gestante}

Nas aulas de canto pré-natal as práticas partiam da premissa de que a escuta é um acontecimento corpóreo, uma experiência dos sons conectada com a subjetividade corporal, com a história de vida de cada corpo. Neste sentido, as propostas vocais envolviam uma jornada interior de cada gestante na escuta do seu corpo, da sua voz, tecendo os seus sentidos nas suas experiências com os sons. Muitas vezes vocalizávamos e cantávamos as músicas de olhos fechados para o exterior e "abertos para o interior", com a intenção de ampliar a escuta da vibração sonora vocalizada, a escuta dos sentimentos e a escuta do bebê no ventre.

No inicio de cada aula os aquecimentos vocais tinham objetivo de convidar as gestantes a entrarem no espaço poético e criativo dos sons, nas dimensões corpórea-afetiva. Mais do que afinar a voz nas escalas melódicas para cantarmos as canções, os aquecimentos vocais envolviam afinar-se a si. Afinar-se a si significa concentrar a atenção à energia interna, desenvolvendo uma observação atenta sobre como está o corpo naquele instante da gravidez. Comenta uma das gestantes que participou dos encontros:

O canto era o gatilho para momentos de trocas intensas entre mulheres grávidas. Logo no primeiro encontro foi possível perceber que para além das técnicas de canto importava a conexão com as necessidades das participantes envolvidas. Cantar e entonar sons foram oportunidades de se autoperceber (Luana, 33 anos).

Com a ampliação da percepção e da consciência sobre si na gestação, impulsos criativos começaram a nascer, conforme comenta uma das gestantes: 
Com estes encontros de canto pré-natal eu descobri o prazer em cantar, em brincar com a própria voz e me arriscar descompromissadamente nos ritmos. A liberdade que eu sentia para cantar naquele espaço, sem expectativas sobre afinação correta ou sobre perfeição era um espaço de alívio em meio às cobranças externas. Quando eu entrava naquela sala, era o acolhimento que prevalecia, e alegria que reinava. Havia uma leveza em nós, que crescia junto ao nosso ventre. Essa experiência me fez liberar um impulso criativo que eu desconhecia em mim, eu voltava dos encontros inventando rimas e cantarolando melodias, que depois foram tomando "corpo" e se tornaram letra e música que eu escrevi para receber meu bem (Juliana, 26 anos).

Entre os exercícios de aquecimento corpóreo-vocal estavam as práticas de respiração. A pedagogia das aulas de voz envolvia ir além do ensino de técnicas e apoios respiratórios para o canto e sim ampliar a consciência do corpo feminino gestante durante as respirações. O escritor alemão Eckhart Tolle traz uma importante inspiração para tema:

Ao ampliar a respiração ocorre a abertura para a sensorialidade do corpo. $\mathrm{O}$ ar que você respira é natureza, como também é natureza o próprio ato de respirar. Preste atenção na sua respiração e perceba que não é você que controla. É a respiração da natureza. Ao sentir a respiração e ao aprender a prestar atenção nela, você se conecta à natureza de forma mais íntima e poderosa (TOLLE, 2005, p.85).

Durante a gestação, a ampliação da consciência da respiração junto com a vocalização contribui no desenvolvimento de percepções refinadas da escuta do corpo, a fim de uma comunicação consciente na relação interativa entre mãe-bebê.

O médico indiano, especialista em Ayurveda, Dr, Deepak Chopra (2005) também sugere a respiração com sons para o corpo relaxar e se abrir: ele orienta a realização do exercício de gemer e suspirar visualizando que a expiração, juntamente com o som, percorre o corpo e sai pelo colo uterino. O obstetra Leboyer (2009) recomenda para o momento do parto que a respiração deve vir do baixo ventre, uma exalação lenta conectada com os movimentos e acompanhada por um som.

Janet Balaskas (2015), no livro "Parto Ativo" constata sobre a importância da respiração no trabalho de parto:

Concentrar-se na respiração inativa a mente, interrompe o diálogo interno que normalmente ocupa o nosso pensamento, e aproxima você de você mesma e do seu bebê. Cada trabalho de parto tem seu próprio ritmo. A concentração nos ritmos da sua respiração vai permitir que você entre em ressonância com este ritmo, instintivamente, e que se renda às forças vitais que atuam dentro de seu corpo (BALASKAS, 2015, p. 174). 
Nas aulas de canto pré-natal, trabalhamos esta consciência da respiração e da vocalização em conexão com o assoalho pélvico, região que estará envolvida no momento do parto natural. Sobre a relação entre o assoalho pélvico, a vocalização e a respiração no trabalho do parto, Jane Balaskas constata:

\begin{abstract}
Quando a mulher tem liberdade para se expressar livremente, uma expiração enorme abre o caminho do nascimento: o diafragma se eleva; o músculo psoas e a pélvis institivamente se inclinam para a frente; o assoalho pélvico se eleva e fica mais plano, enquanto o caminho do nascimento se abre para liberar o bebê (BALASKAS, 2015, p. 95).
\end{abstract}

A fim de aprimorar esta consciência do assoalho pélvico e da respiração nas vocalizações, nas aulas de canto pré-natal vocalizávamos com movimentos da pelve, tais quais os que sugere Balaskas (2015): balançar a pelve para frente e para trás, de um lado para o outro ou em pequenos círculos, entre outros movimentos da pelve. Estes movimentos, diz Balaskas que facilitam a dilatação do colo do útero, a descida do bebê e ajuda a dissipar a dor.

As práticas das aulas de canto pré-natal envolveram cantar canções, mas também envolveram exercícios de improvisação vocal para soltar a voz com o intuito do empoderamento feminino. Nestas práticas, o objetivo era o de deixar sair os sons que brotam do corpo, em um canto espontâneo. Tal liberação da voz ajuda na expressão das emoções durante a gestação e também ajudará na hora do parto. $\mathrm{Na}$ hora do parto: "quando as contrações se tornarem muito fortes emita sons como gemer, grunhir, sibilar, cantar. Não tente coibir essa necessidade que é perfeitamente natural e pode até ajudar a diminuir as dores" (BALASKAS, 2015, p. 204).

Em uma das vivências com tambores que fizemos nas aulas de canto prénatal, o exercício vocal era o de se conectar com a força feminina da "mulher selvagem". O arquétipo da "mulher selvagem" representava a busca pela conexão com a natureza do corpo feminino: o instinto materno, a intuição, o poder de criação, a sabedoria do corpo de gerar e parir. Clarissa Pinkola, no livro "Mulheres que correm com os lobos" descreve o arquétipo da "mulher selvagem" como a natureza mais profunda da mulher, conectada com a percepção aguçada, com o intuitivo, o sexual e o cíclico. Um feminino selvagem que vai além das domesticações das culturas e busca um modo viver uma vida natural. Uma natureza instintiva que implica conectar-se com os próprios ciclos da natureza feminina (PINKOLA, 1999).

A fim de aprimorar a conexão da mulher com a sua natureza corpórea, a metodologia das aulas (a escolha das músicas a serem cantadas, dos instrumentos musicais a serem tocados e as vivências propostas) foi estruturada no arquétipo da "Mãe Terra" e dos 4 elementos da natureza (água, ar, fogo, terra). A partir desta temática cada encontro era composto de uma vivência com visualização criativa, a fim de estimular uma jornada interior de contato com sentimentos relacionados à gestação. Nas palavras de uma gestante que participoou das aulas de canto prénatal: 
Sons de diferentes instrumentos nos permitiram sentir a vibração da música e das vozes no interior do corpo - corpo sensível e belo da gestação - e ter a consciência corporal necessária para se amar e se cuidar. Corpos estes tantas vezes oprimidos e compartimentalizados pela sociedade. Foi esse grupo que me permitiu expressar meus medos, seja ele diante da própria gestação como do parto, de me conectar com outras forças femininas e acima de tudo isso, de ter a liberdade genuína de me ver forte e grata à mãe natureza pela experiência de gestar (Luana, 33 anos).

Nas vivências que invocamos a força do elemento "Terra" trabalhamos a ancestralidade feminina, e para tanto, o instrumento musical utilizado pelas gestantes foram os tambores. Com os sons dos tambores e cantos agradecemos a todas as mães de nossa linhagem ancestral feminina que pariram antes de nós. Sobre esta vivência as gestantes comentam:

Arte, sacralidade, feminilidade e corporalidade em um espaço único e privilegiado. Um ritual, que nos transportou para momentos ancestrais de integração entre as mulheres, seus corpos e o poder contido nesse momento em que uma vida está sendo gerada. Senti muito o processo de cura emocional para com a minha mãe, avós e demais mulheres da minha família (Camila, 33 anos).

No encontro da "terra" foi a primeira vez que comecei a sentir o/a bebê se movimentar, respondendo ao toque dos tambores... estava com 5 meses. Agradecemos a nossa linhagem feminina ancestral e ao final do encontro estava muito segura, empoderada, alegre, com menos dores e sentindo um pouco mais o serzinho que está dentro de mim! (Lohanny, 24 anos).

Durante uma das cantorias, a força do tambor em minhas mãos reverberou na força da ancestralidade que vibrava naquela roda. E eu o senti mexer. Pela primeira vez, eu sentia o movimento de vida da minha cria, que eu ainda não sabia o nome ou mesmo o sexo, mas soube naquele momento que ele me sentia e que ele estava comigo, sentindo o que sentia, vivenciando a magia da força feminina em união. Eu já não me sentia mais sozinha: não conseguia mais disfarçar a emoção que foi aquele momento (Juliana, 26 anos).

Nas vivências que invocamos a força do elemento "Ar" utilizamos instrumentos musicais tais quais: kantele, sinos, carrilhões, kalimba, tigelas de cristal. Em uma das vivências relacionadas ao elemento ar trabalhamos os medos que surgem na gestação e no parto, entregando e confiando. Noutra vivência trabalhamos com as tigelas de cristal aliadas à vocalizações de vogais, nos conectando com a sutileza dos harmônicos e com a voz nos elevando a um estado de total relaxamento. 
Na vivência com o elemento "Água" os cantos eram vocalizados ao mesmo tempo em que em duplas as gestantes lavavam os pés umas das outras, com águas quentinhas com folhas e flores de lavanda, cujo aroma traz uma sensação de relaxamento. A intenção de fazer a lavagem dos pés foi a de gerar uma sensação física de calor, entrega, fazendo a mulher se sentir uma Deusa, sentindo a benção que é ser mulher, que gere e pari. A proposta de lavar os pés era a de gerar sensações que influenciassem na qualidade vocal, na intencionalidade da ação vocal, para que a voz no canto vibrasse conforto e aconchego e assim transmitisse através das ondas sonoras estas sensações ao bebê. Comenta uma gestante:

\begin{abstract}
A vivência de cantar e realizar o escalda pés representou a busca altruísta de mulheres por elas mesmas. O feminino foi contemplado com graça e amor. Minha representação era de conexão do pé com a água e com o ventre, entendendo o momento de compartilhamento feminino na simplicidade e no poder de gerar vida (Luana, 33 anos).
\end{abstract}

Nas vivências musicais as letras das canções atuavam como "chaves" para estimular a jornada interior de contato com as sensações do corpo. "Chaves" no sentido metafórico de que abriam portas internas, convidando cada gestante a entrar em contato com seus medos e forças e demais sentimentos relacionados à gestação, ao parto e à maternidade. As propostas das letras das canções eram sempre estimular o despertar o poder dentro do corpo, da sabedoria e da força feminina; eram vivências de empoderamento através do canto. Duas gestantes que participaram das aulas de canto pré-natal relatam que:

\footnotetext{
As canções nos faziam ir de encontro com as sensações relacionadas ao momento da gestação, ou do parto, ou da maternidade. As letras das músicas tinham um grande poder no papel de empoderamento e de conforto (Franciele, 25 anos).

Vivenciamos realmente o sentido das canções... " que bênção que é nascer, crescer e ser mulher..." e "Bem vindo meu novo Ser, cercado de proteção..." ou ainda de olhos vendados... Entregando e confiando... Ou de "mãos dadas somos mais fortes, plenas, doces, amor... Vem irmã"... "Tudo está bem...". Foram tantos momentos especiais e profundos que vão mais além das músicas e sons ainda ressoando dentro de nós (Michele, 42 anos).
}

Com as vocalizações e os cantos trabalhamos a confiança na sabedoria do corpo feminino e a conexão com o bebê que está se desenvolvendo no útero, enviando vibrações harmônicas para ele. Algumas gestantes que participaram das aulas de canto pré-natal relatam que: 
Percebi o poder da minha voz e da vibração do som em meu corpo, senti e me comuniquei diretamente com a minha bebê ainda dentro da barriga. Uma sensação forte de empoderamento, de tomar consciência da força inata e da capacidade de gerar a vida por meios naturais, vivenciando com alegria cada etapa dessa formação (Camila, 33 anos).

O canto me fez acordar efetivamente para a consciência da vida que estava se desenvolvendo dentro de mim. $\mathrm{E}$ com isso o conhecimento do meu próprio corpo e a sabedoria de que tudo o que eu buscasse para mim, seria transmitido pra minha filha, física e emocionalmente, meus sentimentos de amor foram propagados até ela através do meu canto (Hévila, 31 anos).

Com a harmonia dos cantos e entre chutes brincalhões que me lembravam que eu não estava mais sozinha, fui ganhando força, me tornando consciente de meu poder interior através das técnicas musicais vivenciadas. Após o nascimento dela sinto que existe esse elo na música que nos faz, eu e minha filha, mais próximas (Cláudia, 29 anos).

Por meio das alquimias sonoras, em que mesclamos sons com sentimentos maternais, com inteções e vibrações, aprofundamos a conexão com o que acontece com o corpo feminino durante a gestação, nos conectamos com o bebê no ventre e nos fortalecemos para o parto e para a maternidade.

\section{Conclusão}

As vivências de canto pré-natal realizadas envolveram práticas de voz que permearam vocalizações e cantorias como procedimentos para uma jornada interior, nas dimensões corpóreo-afetivas que envolvem a gestação, o parto e a maternidade.

Os exercícios vocais eram chaves que abriam as portas da conexão com a natureza do corpo feminino. Tinham como objetivos soltar a voz, expressar vocalmente as sensações e os sentimentos, desvendar as relações entre voz, assoalho pélvico e respiração e enviar vibrações sonoras afetivas para o bebê no ventre. As vivências enfatizaram a dimensão aspecto afetiva no ato de cantar: a comuincação vibracional que a gestante estabelecia na comunicação com o filho que está para nascer. Em um grupo de mulheres, juntas realizamos composições de alquimias sonoras que ativavam a sensação de bem-estar em nós e consequentemente nos bebês no ventre.

Com a metodologia de utilizar em cada aula a simbologia da Mãe Terra através de um dos quatro elementos (ar, terra, água, fogo) trabalhamos a conexão dos ciclos da natureza com os ciclos do corpo feminino, buscando a confiança na sabedoria da natureza do corpo.

Estarmos reunidas em um grupo de grávidas criou um espaço de acolhimento e criatividade feminina. Algumas gestantes que participaram do grupo relatam que: 
Nos encontros tomamos contato com a nossa habilidade de apoiar e receber $\mathrm{o}$ acolhimento de outras mulheres para cumprir essa jornada da gestação (Camila, 33 anos).

Estar entre gestantes, em um grupo que acolhe mulheres com distintas idades, fases da gestação e histórias de vida, tem um grande valor, pois, tanto é um espaço para o fortalecimento de sentimentos de acoIhimento, como também para práticas de encorajamento (Franciele, 25 anos).

Reunir várias gestantes num mesmo espaço e compartilhar esse afeto maternal através da musica foi uma experiência única. A força que nós mulheres podemos construir juntas, a ponte que se forma quando estamos nesse momento tão especial que é o gestacional, me fez sentir mais preparada para o momento do parto, criou em mim a coragem que eu precisava. Na hora do parto pude cantar as músicas que aprendi, e canto até hoje pra tranquilizá-la (Hévila, 31 anos).

O projeto 'Cantos de Gaia' cumpre um papel essencial de integração entre a arte e o cuidado. A arte vem da música, do canto, da experiência com diversos instrumentos musicais; o cuidado vem através da possibilidade de um momento em grupo, onde permite-se a completa entrega, proporcionando momentos meditativos e de profunda conexão consigo mesmo, estendendo-se a conexão com o bebe dentro do útero. Essa junção permite a formação de um grupo terapêutico, em que emoções são vivenciadas e trabalhadas de forma plena (Lara, 28 anos).

Nos encontros nos nutrimos com cantos femininos relacionados à força criadora da natureza e da gestação, parto e maternidade e unidas honramos nossos ventres, soltamos a voz e cantamos celebrando a vida.

\section{Referências}

CABRERA, Julio. "Musicoterapia y pediatria". Revista Peruana de Pediatria, vol.58, n.1. 2005. Disponível em <http://sisbib.unmsm.edu.pe/bvrevistas/rpp/v58n1/contenido.htm> Acesso: 11 de junho de 2016.

CHOPRA, Deepak. Origens mágicas, vidas encantadas. RJ: Rocco, 2005.

BALASKAS, Janet. Parto Ativo: guia prático para o parto natural. São Paulo: Ground, 2015.

FEDERICO, Gabriel; WHITWELL, Giselle. Music Therapy and Pregnancy. Journal of Prenatal \& Perinatal Psychology \& Health, Vol. 15, No. 4, Summer 2001. Disponível em <https://birthpsychology.com/journals/volume-15-issue-4/music-therapy-and-pregnancy>. Acesso: 18 de junho de 2016.

FEDERICO, Gabriel. Música Prenatal. Buenos Aires: Kier, 2003. 
El embarazo musical. Buenos Aires: Kier, 2004.

Melodias para el bebe antes de nacer. Buenos Aires: Kier, 2004.

Viaje musical por el embarazo. Buenos Aires: Kier, 2013.

GOLDMAN, Jonathan. Chakra Frequencies. USA: Destiny Books, 2011.

The 7 secrets of sound healing. USA: Hay house, 2008.

Shifiting Frequencies. USA: Light Technology Publishihng, 1998

LEBOYER, Frédérick. The art of giving birth, with chanting, breathing and movement. USA: Healing Arts Press, 2009.

NUNES, Patricia Alexandra Oliveira. Experiência auditiva no meio intrauterino. [Mestrado em Psicologia] Faculdade de Psicologia e Ciências da Educação da Universidade de Coimbra, Portugal, 2009. Disponível em <http://www.psicologia.pt/artigos/textos/TL0157.pdf>. Acesso: 18 de junho de 2016.

PINKOLA, Clarissa. Mulheres que correm com os lobos: mitos e histórias do arquétipo da mulher selvagem. Rio de Janeiro: Rocco, 1999.

TOLLE, Ekhart. O poder do silêncio. Rio de Janeiro: Sextante, 2005.

GAYNER, Mitchel. Sons que curam. SP: Cultrix, 1999.

TOMATIS, Alfred. A noite uterina. Lisboa, Instituto Piaget, 1987.

Recebido em 26/02/2017 Aprovado em 22/08/2017 